\title{
EL NUEVO URBANISMO DEL BAJO SEGURA A CONSECUENCIA DEL TERREMOTO DE 1829
}

\author{
Gregorio Canales Martínez
}

El planeamiento urbano como ciencia y como disciplina tiene un origen muy reciente, pues aun cuando para las grandes ciudades se considera iniciado en la segunda mitad del siglo XIX en virtud de los planes de ensanche, para los restantes municipios, el urbanismo ha sido consecuencia de la improvisación y de la espontaneidad, lo que en muchas ocasiones ha desembocado en un trazado urbano anárquico, irracional, y en discordancia con el medio natural en que se desarrollaba.

La administración pública no ha sido ajena a las preocupaciones ciudadanas, esforzándose cada vez más por un urbanismo racional que contribuya a hacer habitables las ciudades, y a mejorar en definitiva la calidad de vida.

El objeto y contenido de este estudio es la reconstrucción de los pueblos situados en la comarca alicantina del Bajo Segura como consecuencia de la catástrofe que causó el terremoto de 21 de marzo de 1829, reconstrucción llevada a cabo con un criterio lógico, tanto en su proyección como en la utilización de los siempre limitados recursos económicos.

\section{SISMOLOGÍA DEL BAJO SEGURA}

Resulta necesario, antes de entrar en la exposición de los hechos acaecidos como consecuencia del terremoto que en el año 1829 asoló la comarca del Bajo Segura, intentar al menos reflejar y delimitar las condiciones físicas de la zona que propiciaron y son origen del mismo.

La comarca del Bajo Segura constituye el foco sísmico más relevante del Sureste peninsular ${ }^{1}$ quedando comprendida según Rey Pastor entre las siguientes líneas: Al norte limita con la de Fortuna-Abanilla-Santa Pola, que la [150] separa de la comarca de Alicante, y al suroeste con la de Fortuna-Mar Menor que deja al otro lado las comarcas del medio Segura y Cartagena.

Se distinguen tres importantes núcleos sísmicos en la comarca del Bajo Segura², el de Benejúzar, que integra el conjunto de epicentros diseminados entre Orihuela, Bigastro, Jacarilla, Benejúzar y Redován; el núcleo de Rojales, que abarca las poblaciones de Almoradí, Algorfa, Benijófar, Formentera, Daya Nueva, Daya Vieja, San Fulgencio, Guardamar y Rojales; y por último el núcleo de Torrevieja, que se circunscribe al pueblo de este nombre y a sus caseríos inmediatos.

De los tres núcleos sísmicos mencionados el de mayor importancia es el de Benejúzar, seguido de Torrevieja y Rojales, que conjuntamente forman una comarca que en cuanto a sismicidad ocupa el segundo lugar dentro de la Península, después de la de Granada, incluyéndose en el grupo $6^{\circ}$ de Sieberg como «zonas plegadas en épocas relativamente próximas en las cuales han tenido lugar importantes fragmentaciones de ruptura» (grupo que aglutina el $24 \%$ de los sismos mundiales).

\footnotetext{
${ }^{1}$ REY PASTOR, A.: Sismicidad de la comarca costera alicantina. Instituto Geográfico y Catastral, Madrid 1948, pág. 13.

${ }^{2}$ REY PASTOR, A.: La Comarca sísmica del Bajo Segura. Instituto Geográfico y Catastral, Madrid 1943, págs. $1-41$.
} 
Los núcleos de Benejúzar y Rojales están situados en la línea sismotectónica del Bajo Segura y contienen dos fallas, una la de Benejúzar-Benijófar y la otra la de Guardamar, la primera procede del hundimiento del bloque septentrional en la época post-pliocena y segunda del desplazamiento de bloques menos acenturados. El núcleo de Torrevieja se sitúa en el extremo sur de la falla de su mismo nombre que cruza a la anterior y está delimitado por la fosa tectónica de la rambla de Benferri así como por diversas pequeñas fallas en Hurchillo y Los Montesinos.

Entre los núcleos sísmicos periféricos a la comarca, aunque de muy inferior intensidad y frecuencia, cabe citar a los formados por la línea Crevillente-Cabo de la Nao y por la línea del Sangonera; ésta última que se extiende desde Lorca hasta Callosa del Segura afecta a la comarca del Bajo Segura en su último segmento.

Esta red de fallas configura una serie de piezas corticales, resultantes de los efectos de diastrofismo y descompresión ocurridos en el período postorogénico alpino; esas piezas son, con la del Mar Menor, la del bloque costero alicantino, que afecta a nuestra comarca; y la del bloque de Torrevieja, de dimensiones más reducidas; entre estos dos últimos bloques se encuentra la falla del Bajo Segura, que es sede de los focos sísmicos más violentos.

El bloque costero alicantino, situado al norte de dicha falla, está hundido, a menos de 10 metros de altura media, respecto al bloque de Torrevieja, que se eleva hasta $200 \mathrm{~m}$ sobre el anterior. Este último desempeña el papel de pieza intermedia entre el bloque móvil costero alicantino y el bloque, casi estable, del Mar Menor. Las tendencias de estos bloques corticales a un ajuste isostático [151] origina convulsiones sísmicas en las líneas de contacto ${ }^{3}$, la principal de las cuales es la falla del Bajo Segura.

De ordinario los focos sísmicos del Bajo Segura son convulsionados con una frecuencia de 10 a 12 sacudidas ligeras al año, y tienen una característica tectónica-epirogénica, y, como queda dicho, su causa principal es el movimiento de ajuste de los bloques corticales fuertemente afectados por la formación de los óvalos mediterráneos, por lo que son de mayor violencia que los movimientos sísmicos de la cuenca media del Segura, de carácter tectónico normal, con una profundidad hipocentral en algunos sismos que oscilan entre los 10 a $25 \mathrm{Km}$. según estudios de Rey Pastor.

\section{El terremoto de 1829}

Desde el siglo IX -en el que ya existe constancia de movimientos sísmicos ${ }^{4}$ - hasta la actualidad, se puede afirmar que el período comprendido entre 1828 a 1830 es el que registra las mayores desgracias en la comarca del Bajo Segura como consecuencia de constantes y sucesivas sacudidas sísmicas.

Según dice Rey Pastor los tristes sucesos comenzaron el 13 de septiembre de 1828 con una sacudida de grado VIII y se prolongaron casi ininterrumpidamente a lo largo de seis meses contabilizándose más de doscientos temblores en setenta y tres días, cuya violencia se comprendía entre III y IV grados y cuyos efectos se dejaron sentir en todos los pueblos de la comarca.

Sin embargo, el movimiento más fuerte tuvo lugar el 21 de marzo de 1829 llegando a un grado $\mathrm{X} 1 / 2 \mathrm{y}$ originó la destrucción total de algunas localidades del Bajo Segura y graves daños para las restantes poblaciones.

A título significativo transcribimos un párrafo del texto enviado por el Obispo de

${ }^{3}$ REY PASTOR, A.: Estudio sismotectónico de la región Sureste de España. Instituto Geográfico y Catastral, Madrid 1951, pág. 23.

${ }^{4}$ RODRÍGUEZ DE LA TORRE, F.: «Catálogo sísmico de la actual provincia de Alicante (hasta el final del siglo XVIII)». Instituto de Estudios Alicantinos, Alicante 1980, N. ${ }^{\circ}$ 30, págs. 107-133. 
Orihuela a S.M. el rey Fernando VII dando cuenta de lo acaecido: «el 21 del corriente, sábado al anochecer, sucedió el espantoso terremoto del que ya tendrá noticia V.M. A las 11 de aquella misma noche principié a recibir avisos de los curas..., sobre las desgracias y ruinas de sus respectivas parroquias y pueblos. Los de Almoradí, Benejúzar, Rafal, Formentera, Torrevieja y Torre La Mata han sido totalmente asolados, sin que quede en ellos una sola casa habitable. Poco menos sucede a los de Rojales y Guardamar, y en sus huertas y campos. En los de esta ciudad (Orihuela) se contarán 2.000 casas igualmente asoladas, de modo que en tres o cuatro leguas de longitud y latitud, incluso los pueblos dichos, se ven arruinadas de 3 a 4.000 casas..., 10 Iglesias parroquiales enteramente destruidas, y otras tantas ruinosas...» ${ }^{5}$. [152]

Hasta septiembre de 1830 continuaron de forma irregular los temblores sísmicos, sumiendo a la población en un temor constante durante dos años. El área epicentral de grado X comprendió los núcleos urbanos de Benejúzar, Rojales y Torrevieja, y el área de conmoción afectó a las regiones oriental y central de la Península, lo que hace de este sismo el más intenso de todos los ocurridos en la zona de Murcia-Alicante.

El terremoto fue más violento en las orillas del río Segura debido a la facilidad de propagación del movimiento en el terreno aluvial y algo menos en los lugares apartados de sus riberas. A excepción de Torrevieja, todos los núcleos afectados se encuentran o bien en las márgenes del río, como Benejúzar, Rojales, Formentera y Guardamar, o bien próximos a él, como Almoradí, Dolores, San Fulgencio, etc. (figura 1)

Los partes que los alcaldes de los pueblos de la comarca enviaban a Orihuela en los días siguientes al terremoto ponen de manifiesto las terribles consecuencias del mismo, con unas poblaciones que han resultado asoladas por la catástrofe, viviendo sus habitantes horas de angustia $^{6}$. En los pueblos afectados se levantaron barracas y chozas para albergar a sus moradores, barracas construidas -como describen textualmente los citados partes- "con los propios palos de sus casas y con cuatro esteras el que las tenía». En los pueblos no destruidos totalmente, como Dolores, Redován y San Fulgencio, la gente se vio forzada a abandonar sus casas y acampar en la huerta debido a la frecuencia con que se sucedían los temblores, patética situación que se vio agravada ante la falta de alimentos y de medicinas, ya que los graneros, molinos, hornos, boticas, almazaras, etc., se habían convertido en escombros.

Las comunicaciones evidentemente también resultaron afectadas, principalmente por la destrucción de los puentes de Almoradí, Benejúzar, Dolores y Guardamar, desdibujándose las márgenes del río en algunos puntos de su recorrido que «quedaron bajo el agua con los árboles que las soportaban». En consecuencia, desaparecieron las defensas contra las inundaciones, en Almoradí, Benijófar y Rojales quedaron asolados los azudes de riego con graves perjuicios para la agricultura, e infinidad de boqueras se abrieron con el terremoto (520 en Benijófar, 400 en San Fulgencio, 150 en Rafal, etc.) «boqueras que por las lejías que despedían secaban las plantaciones».

Numerosas fueron las víctimas causadas por el terremoto del citado día 21 de marzo de 1829. De los 399 fallecidos, el 50\% pertenecían a la localidad de Almoradí, siguiéndole Rojales y Benejúzar con un $25 \%$ y un $12 \%$, respectivamente, del total de defunciones (vide, figura 2 ). El arquitecto autor de los posteriores proyectos urbanísticos, Larramendi, señala en sus «Memorias» que en Almoradí perecieron mayor número de personas en razón de contar

\section{[153]}

${ }^{5}$ ANÓNIMO: Los terremotos de Orihuela o Henrique y Florentina (Historia trágica). Valencia 1829, pág. 4.

${ }^{6}$ ARCHIVO MUNICIPAL DE ORIHUELA: Partes de los alcaldes de los pueblos del Bajo Segura, mandados a Orihuela, comunicando las desgracias causadas en cada localidad por el terremoto. Año 1829 , legajo N. ${ }^{\circ} 172$ (s.f.). 


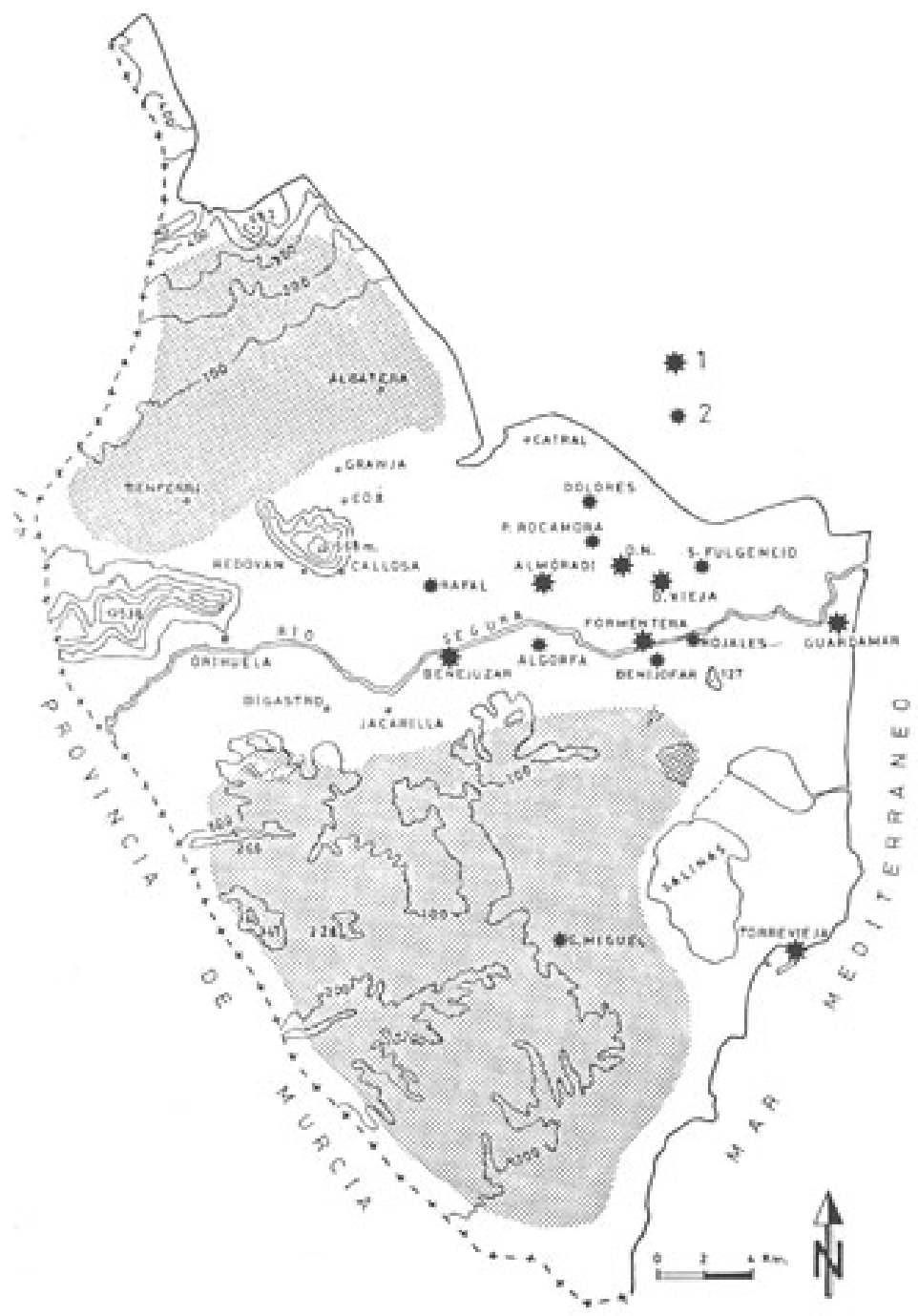

FIGURA 1. Mapa de la comarca del Bajo Segura. Nótese que la gran mayoría de poblaciones se ubican en la llanura aluvial del río Segura, entre las dos zonas de «campo» o secano (punteadas en el mapa).

1. Poblaciones totalmente destruidas por el seísmo de 21 de marzo de 1829.

2. Poblaciones afectadas parcialmente por el mismo. [154] 


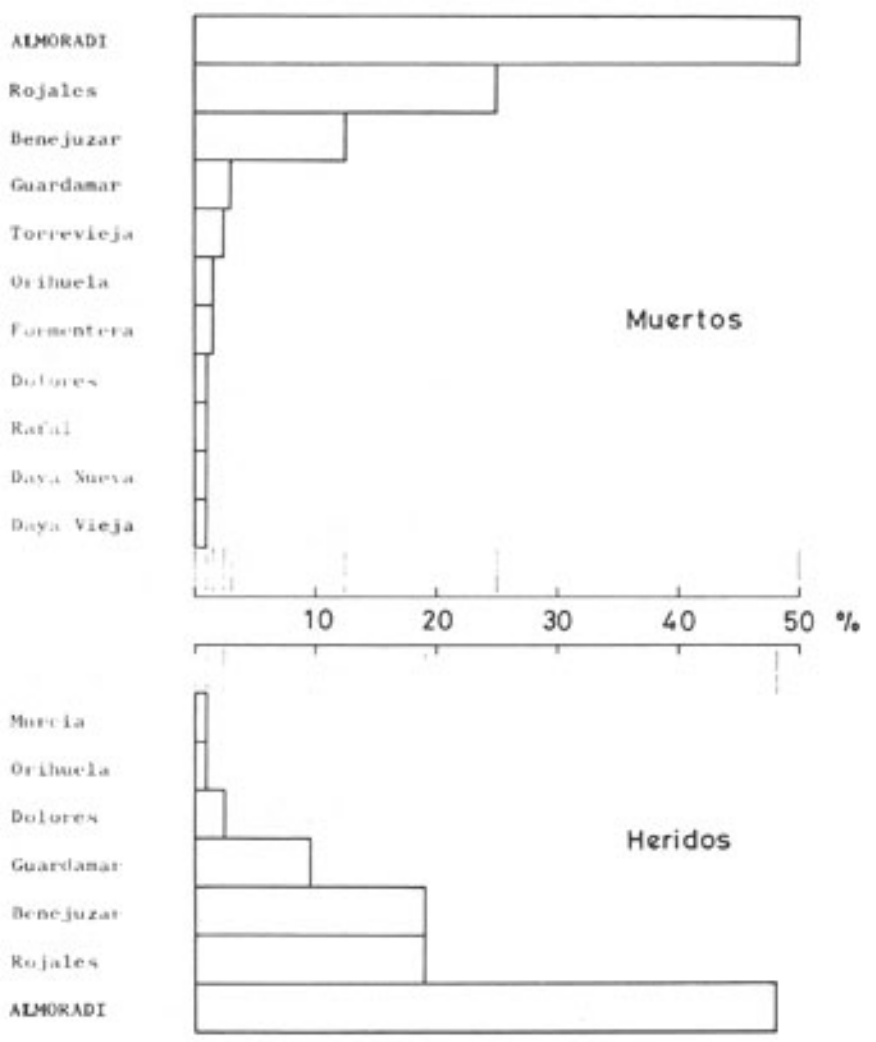

FIGURA 2. Distribución de las víctimas causadas por el terremoto de 1829 en las distintas localidades, expresadas en tantos por cien sobre los totales de muertos y heridos.

con calles estrechas y edificios de varios pisos ${ }^{7}$; de ahí que en el trazado de las nuevas poblaciones realizara calles de gran anchura. Los heridos alcanzaron el número de 209; los de los pueblos costeros fueron trasladados por barcas a Alicante y a Cartagena, y los del interior, mediante carros, hacia Orihuela, donde el Obispo de la diócesis había improvisado un hospital.

La prensa se ocupó ampliamente de la catástrofe ocurrida, lo que coadyuvó a crear un sentimiento de solidaridad nacional, e incluso internacional, con los pueblos afectados. El mismo rey Fernando VII promovió una ayuda en favor de los necesitados, disponiendo: «He mandado que de mi bolsillo secreto y el de la Reina, mi augusta Esposa, se suministre inmediatamente 1.500.000 reales... Asimismo he venido en decretar, que de los granos de rentas decimales pertenecientes a mi Corona, se apliquen con el mismo destino 20.000 fanegas de trigo»». Inmediatamente después del terremoto, el 5 de abril de 1829, se publicó un decreto dirigido a todas las corporaciones y habitantes del país con un llamamiento de unánime solidaridad para

${ }^{7}$ LARRAMENDI, J. A.: Memoria y relación circunstanciada de los estragos que la terrible catástrofe de los terremotos de 21 de marzo y siguientes, principalmente el del sábado santo 18 de abril hasta el presente día, han causado en Torrevieja y demás pueblos de la gobernación de Orihuela y sus inmediaciones, en la ciudad de Murcia y algunos pueblos de la provincia de este nombre.

Madrid, 1829; Imprenta Real, págs. 1-24. 
que, siguiendo el ejemplo del monarca, contribuyeran con sus donativos a una campaña de ayuda $^{8}$, abriéndose a tal fin una suscripción nacional en la que colaboraron también españoles residentes en Europa y América9

A nivel nacional se constituyeron dos Juntas, una comisionada para averiguar las pérdidas sufridas y censar las personas necesitadas de socorro y otra para decidir el destino de los fondos recaudados. Las primeras ayudas tanto en metálico como en alimentos provinieron de las ciudades próximas de Orihuela ${ }^{10}$ y Alicante $^{11}$, pero la respuesta fue unánime y las esperanzas depositadas en la suscripción popular no resultaron defraudadas. La recaudación ascendió a 8.460.854 reales de vellón, además de algunas partidas en alimentos recogidas por los párrocos y justicias de cada localidad, que, a su vez, se encargaron de confeccionar las listas de donantes (publicadas en la Gaceta de Madrid de fechas 16 de abril de 1829 al 10 de junio de 1830).

\section{LOS NUEVOS PUEBLOS SURGIDOS DEL TERREMOTO: PLANEAMIENTO GENERAL URBANO}

De los pueblos destruidos totalmente por el terremoto, los de Almoradí, [156] Benejúzar, Guardamar y Torrevieja, fueron edificados de nuevo por mandato de Fernando VII con los fondos recaudados; fondos que también se emplearían en las restantes poblaciones afectadas, como Formentera, Benijófar, Daya Nueva, etc., las cuales contaron además con la ayuda de los respectivos dueños territoriales para la recomposición de sus viviendas.

Los planos de los nuevos trazados urbanos se conservan en el archivo del Palacio Real de Madrid $^{12}$. Dichos planos fueron realizados por el arquitecto D. José Agustín de Larramendi y aprobados por Real Orden de 6 de junio de 1829, mediante la que se nombraba superintendente de las obras al Obispo de Orihuela, D. Félix Herrero Valverde y como director ejecutivo a D. Eugenio Fourdinier, el cual era asistido en cada localidad por un encargado.

Con vistas a la ayuda económica o financiación que se debía facilitar para la construcción de las viviendas, agruparon los vecinos de cada población en tres categorías: los que carecían de recursos; los que, aun contando con algunos medios, precisaban de ayuda económica, y por último, las personas pudientes. A los primeros se les facilitaba la casa ya construida, a los segundos se les señalaba la superficie de la vivienda y su situación en cada manzana, aportándoles los medios económicos a medida que presentaban las facturas de la construcción. A los últimos se les reservaba la misma situación y superficie que tuviesen sus viviendas antes del terremoto, debiéndolas levantar por su cuenta, y si por cualquier circunstancia no pudieran terminar su ejecución, las continuaba la empresa encargada de las obras, previo compromiso de amortización por el dueño, y ello porque el objetivo previsto era que en las nuevas calles proyectadas no quedara ningún solar sin edificar ${ }^{13}$.

Todas las casas, sin excepción alguna, eran de planta baja, con un corral interior para que,

\footnotetext{
${ }^{8}$ GACETA DE MADRID, martes 7 de abril de 1829, N. ${ }^{\circ}$ 42, pág. 165.

${ }^{9}$ GACETA DE MADRID, martes 6 de abril de 1830, N. ${ }^{\circ}$ 41, pág. 174.

${ }^{10}$ VIDAL TUR, G.: Un obispado español el de Orihuela-Alicante, Alicante 1962, t. II, pág. 415.

${ }^{11}$ VIRAVENS y PASTOR, R.: Crónica de la ciudad de Alicante. Alicante 1976 (facsímil de la edición de 1876), pág. 443.
}

\footnotetext{
${ }^{12}$ Nuestro agradecimiento a D. Justo García Morales, por la ayuda prestada para la realización de este estudio.

${ }^{13}$ ARCHIVO MUNICIPAL DE TORREVIEJA: Carpeta sobre el terremoto de 1829 (varios documentos, s.f.).
} 
al menor temblor, sus habitantes pudieran salir a un espacio abierto o a la calle en evitación de futuras desgracias.

Para un adecuado control de costes y una buena distribución de los recursos económicos, a cada manzana se le asignaba un presupuesto, de manera que todas las casas construidas en la misma no lo excedieran. Como dato experimental se construyó una manzana de casas para los que carecían de recurso alguno, sirviendo sus costes para que las demás contratas se efectuaran correctamente. El reparto de recursos, la situación y superficie de las casas, dentro siempre del plan general, quedaban al prudente juicio del superintendente, con el fin de evitar las dilaciones y demoras que resultarían de un sistema de expedientes particulares.

Entre sus atribuciones el superintendente contaba también la de abrir canteras donde se hallaran materiales de mejor calidad, expropiando los terrenos precisos, previa las oportunas indemnizaciones a sus dueños. [157]

Una vez trazadas las manzanas, en calles espaciosas de 14 a 17 metros de ancho, se levantaban en primer lugar las fachadas con las paredes paralelas y los correspondientes tejados, a fin de respetar el trazado, y la posterior distribución interior quedaba a criterio de sus ocupantes, quienes asimismo disponían de la facultad de colocar en las fachadas los adornos que les apeteciese, pero siempre sujetándose a la alineación proyectada y a la misma altura, que, según las calles, oscilaba entre 4 y 5 metros.

A fin de defenderse del sol estival, dadas la acusada horizontalidad de las edificaciones y la anchura de calles, los vecinos estaban obligados a plantar delante de sus viviendas y en el sitio previsto por el director de las obras, el número de árboles que se les asignasen de manera que estos pueblos, como señala su arquitecto «vendrán a estar en unas hermosas alamedas... y ofrecerán una comodidad y delicia que nada habrá que sea comparable en España» ${ }^{14}$.

La planimetría de las nuevas construcciones se efectuó considerando tres elementos esenciales: las plazas, las calles y los solares, componiéndose de esta manera las relaciones zona edificable-no edificable y espacio público-espacio privado, todo ello formado por un trazado de líneas perpendiculares y paralelas dentro de una trama ortogonal, que es la base del modelo urbanístico utilizado, en la que destaca la plaza mayor alrededor de la cual se desarrolla el conjunto urbano. Además de centro geográfico la plaza constituye el centro simbólico de la población, al situarse en ella los principales edificios públicos, administrativos y religiosos, convirtiéndose asimismo en el centro comercial, por ser el lugar de mayor accesibilidad y de intersección de las calles principales y en donde aún hoy día se celebra habitualmente el mercado una vez a la semana.

El modelo urbano empleado en estas poblaciones del Bajo Segura tiene su antecedente en la experiencia universal de fundación de ciudades siguiendo la cuadrícula, remontándose a las ciudades hipodámicas de la civilización griega, a los castros romanos y a las bastidas francesas.

Nuestro país cuenta con una gran tradición en el empleo de la cuadrícula como base de la planimetría de las ciudades, sistema que ya se utilizó en la época medieval, durante la reconquista. Es el caso de las villas creadas por los reyes de la monarquía aragonesa-catalana en las fértiles huertas valencianas, tales como Castellón, Nules, Villarea $1^{15}$, etc., que abandonan sus antiguos emplazamientos en lugares enriscados para formarse en los llanos y con unas características urbanas muy similares a las antes expuestas. Método que fue implantado por los españoles en el Nuevo Mundo y cuyo antecedente más inmediato fue la ciudad de Santa Fe de

\footnotetext{
${ }^{14}$ Larramendi: Op. cit., pág. 20.

15 TORRES BALBAS, L.: «La Edad Media». GARCÍA BELLIDO, A., y otros, Resumen Histórico del urbanismo en España, IEAL, Madrid 1968, pág. 121.
} 
Granada, fundada en 1490 .

Al igual que la polis constituyó en Grecia el elemento catalizador del desarrollo [158] de la cultura de la civilización helénica, la ciudad representa un componente esencial de la colonización y del dominio de los españoles en las nuevas tierras. Este modelo de ciudad se desarrolla en América desde el siglo XVI hasta la época de las Independencias nacionales de principios del siglo XIX, extendiéndose desde el sur de EE.UU. hasta el sur de Chile y Argentina, con arreglo a las Ordenanzas dadas por Felipe II en $1573^{16}$.

Idéntica estructura se siguió en los poblados levantados en el siglo XVIII en Andalucía para proteger la primera ruta comercial del país, la carretera de Madrid a Cádiz. Localidades como La Carolina, La Carlota, Carbonera, Santa Elena y Lusiana, etc., muestran su trazado ortogonal con plazas hexagonales, o de más lados, incluso casi circulares, siendo ésta la única variante típica de las mismas ${ }^{17}$.

También en el siglo XIX y al margen de las poblaciones reconstruidas que son objeto de este estudio, se llevó a cabo la reedificación de otras localidades arrasadas por los terremotos y cuyo trazado es muy similar al empleado en el Bajo Segura. En este sentido hay que citar la labor realizada en algunos pueblos de Andalucía (Alhama, Arenas del Rey, Albuñuelas, Güevejar, etc.) como consecuencia del terremoto del día de Navidad de $1884^{18}$.

La urbanización bajo el trazado en cuadrícula llegó a generalizarse siendo utilizada en los ensanches de las grandes ciudades, Madrid y Barcelona en 1860, San Sebastián en 1864, Bilbao en 1876 y Zaragoza en $1894^{19}$.

\section{La reconstrucción urbana en el Bajo Segura tras el seísmo de 1829}

Serían necesarios tres años hasta culminar la terminación de las obras en los pueblos destruidos por el terremoto. Con fecha 26 de marzo de 1832 el superintendente, Obispo de Orihuela, enviaba una relación al rey de todo lo llevado a cabo: «Se han reedificado 750 casas de las arruinadas por los terremotos en los campos y huertas, y se han reedificado molinos de aceyte y arineros. Se han compuesto y habilitado puentes. Se han construido cuatro pueblos nuevos, y en ellos 1.282 casas, y se han hecho en los mismos la plantación general de árboles en sus plazas, calles y ejidos. Todo conforme a los planos del Ingeniero Director General de Correos y Caminos, D. José Agustín de Larramendi, enviado por V. M. a el efecto, y que V. M. se dignó aprobar. Se han recompuesto, además, las casas de todos los pueblos restantes, que fueron en número de 971. Y por fin, Señor, el Santo de los Santos, el [159]

\footnotetext{
${ }^{16}$ AGUILERA ROJAS, J.: «Teoría urbanística en la colonización española de América. Las ordenanzas de Nueva Población», Ciudad y Territorio N. ${ }^{\circ}$ I, Madrid 1977, pág. 9.

${ }^{17}$ CHUECA GOITIA, F.: «La Época de los BORBONES». GARCÍA BELLIDO, A. y otros, Resumen histórico del urbanismo en España, IEAL, Madrid 1968, pág. 239.

${ }^{18}$ QUIRÓS LINARES, F.: «Notas sobre núcleos de población española de planta regular», Estudios Geográficos, N. ${ }^{\circ}$ III, Madrid 1968, pág. 313. 6.

${ }^{19}$ LARRODERA, E.: «Evolución del planeamiento en España», Ciudad y Territorio, N. ${ }^{\circ}$ 4, Madrid 1972, pág.
} 


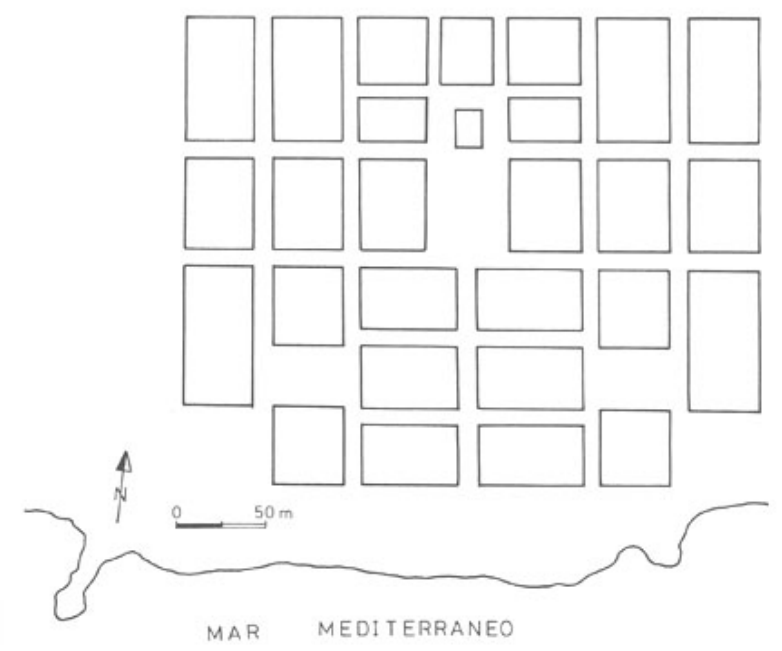

FIGURA 3. Planta hipodámica de la reconstrucción de Torrevieja posterior al seísmo de 1829. Se aprecia como respecto a la figura 4 que la extensión reedificada fue sensiblemente menor que la ocupada por la población anterior. [160]

Augusto Sacramento del Altar, ya no está en 17 barracas en que ha estado por dos años o más, y si en otras parroquias, recompuestas las unas y construidas otras provisionalmente hasta que estén concluidas las que se reedifican de nuevo... ${ }^{20}$. Con posterioridad a dicho escrito se levantarían algunas viviendas más, hasta hacer un total de 3.108 nuevas o recompuestas edificaciones.

En las poblaciones de Almoradí y Torrevieja la reconstrucción se efectuó sobre el mismo suelo que ocupaba el anterior casco urbano; no así en las de Benejúzar y Guardamar, en las que se buscó un emplazamiento más favorable aunque próximo al anterior, mediante las necesarias expropiaciones e indemnizaciones a los dueños de los terrenos ocupados, previa tasación pericial, lo que llegó a representar un montante de indemnizaciones por valor de 10.771 reales para Benejúzar y 16.000 para Guardamar, cantidades sensiblemente inferiores a las gastadas en la ampliación de suelo para la nueva edificación del Almoradí, capítulo que contó con una inversión de 183.685 reales, muy superior a la de aquellas dos poblaciones, en función de la distinta calidad del suelo ocupado, que era de regadío en la localidad de Almoradí. En Torrevieja, debido a la menor superficie del nuevo trazado urbano respecto a su casco anterior, no fue necesaria inversión alguna en la adquisición de suelo.

Con la reconstrucción, los habitantes de estas localidades iban a gozar de unas viviendas mejores a las que poseían con anterioridad al terremoto, aunque siempre primó el sentido de lo necesario, sin concesiones a lo superfluo. En cada pueblo se construyeron por lo general igual número de viviendas que antes, buscándose siempre una cierta proporción e igualdad, como se desprende de la memoria del arquitecto quien especifica que las casas más pequeñas no tendrán menos de 10 metros de fachada y 14 de fondo, y las mayores desde 20 a 34 metros de fachada y 15 a 24 de fondo. Se proyectó una construcción sencilla pero a la vez resistente: «se empleará

${ }^{20}$ GACETA DE MADRID, jueves 24 de mayo de 1832, N. ${ }^{\circ}$ 62, pág. 255. 
mucha enmaderación, muy trabada entre sí, y con la fábrica de mampostería, a fin de que sea más difícil el desprendimiento de sus partes en cualquier movimiento» ${ }^{21}$.

Torrevieja se reedificó en el mismo suelo que ocupaba con anterioridad, y ello pese a la oposición de sus vecinos que pretendieron el traslado más al sur, en dirección hacia Cartagena, apoyando sus reivindicaciones en que en ese lugar no se había destruido ningún edificio durante el terremoto, pero la existencia del puerto y la explotación salinera obligaron a respetar su anterior emplazamiento, levantándose 268 casas en 27 manzanas de 61 y 88 metros de frente por 64, 94 y 101 metros de fondo; de planta cuadrada, con cinco calles en dirección hacia el mar, a su vez cruzadas por otras tantas calles, entramado que comprende en su interior tres plazas, ubicándose la iglesia en la plaza central, la de mayor superficie (figura 3).

Como quedó dicho, la superficie construida en Torrevieja fue más reducida que la anterior, pues, según el arquitecto, se debían construir las casas necesarias [161] para las personas empleadas en la explotación de las salinas, objetivo prioritario de la localidad, pretendiéndose con esta medida suprimir el contrabando que constituía con anterioridad el origen de los recursos de gran parte de su población. En cualquier caso dicha medida no debió resultar muy eficaz puesto que, años después, se observa que los alrededores de Torrevieja están formados por multitud de barracas aglomerada sin orden alguno, lo que desmerece «la belleza y simetría del casco de la villa $\rangle^{22}$, considerándose que no había otro estímulo para establecerse que el motivado por el contrabando.

Sin embargo, entre todas las poblaciones reconstruidas, la de Torrevieja es la que tuvo un trazado urbano más semejante al que ofrecía antes del terremoto, seguramente por tratarse de la población de origen más reciente, ya que fue creada en el año 1802 al trasladarse las oficinas de las salinas desde La Mata a Torrevieja, edificándose las casas, previa licencia expedida por el administrador de la explotación salinera, que estaba autorizado para la concesión de las mismas con arreglo a un mapa que se le ordenó formar y que fue aprobado el 3 de marzo de 1803, iniciándose las obras en los terrenos que a tal efecto el Ministerio de la Guerra había cedido al Ministerio de Hacienda (figura 4).

Al igual que Torrevieja, Almoradí se reedificó en el mismo suelo que ocupaba antes del terremoto, pero fue precisa una superficie bastante mayor, debido al nuevo trazado de sus calles y a la edificación de casas de planta baja, lo que no era usual en dicha localidad, que, por su origen más antiguo ${ }^{23}$, tenía una planimetría anárquica, con calles estrechas y edificios de varios pisos, amontonados irregularmente alrededor de la iglesia, lo que motivó que sufriera el mayor número de víctimas durante el terremoto.

La villa reconstruida tuvo una planta rectangular de 525 metros de largo por 280 metros de ancho; su interior se distribuye en cinco calles longitudinales cortadas por otras cinco perpendiculares, donde se levantaron 26 manzanas con 335 viviendas, dejando en su centro una plaza muy espaciosa de 155 metros de largo y 95 metros de ancho. Tanto las calles como la plaza y los ejidos fueron plantadas de árboles de morera. La ejecución de la obra hizo preciso embovedar un brazal de riego de la acequia principal, que representaba un obstáculo para el nuevo trazado (figuras 5, 6 y 7).

La mayor reedificación se efectuó en Guardamar con 540 viviendas en 34 manzanas similares a las de Almoradí, de 108 metros de frente por 27, 30 y 40 metros de fondo,

\footnotetext{
${ }^{21}$ LARRAMENDI: Op. cit., pág. 21.

${ }^{22}$ MADOZ, P.: Diccionario Geográfico-Estadístico-Histórico de España y sus posesiones de ultramar. Madrid 1845-1850, t. XV, pág. 104.

${ }^{23}$ En efecto, ya a finales del XVI Almoradí debía tener cierta entidad, cuando logra su segregación respecto a Orihuela. Vid. GISBERT, E.: Historia de Orihuela, T. I, Orihuela, 1903, Imp. Cornelio Paya, pág. 561.
} 
desarrollándose de forma rectangular sobre cinco calles cortadas por seis perpendiculares, situándose la iglesia en medio de una amplia plaza de 168 metros de largo y 81 de ancho, frente al Ayuntamiento. En los [162]

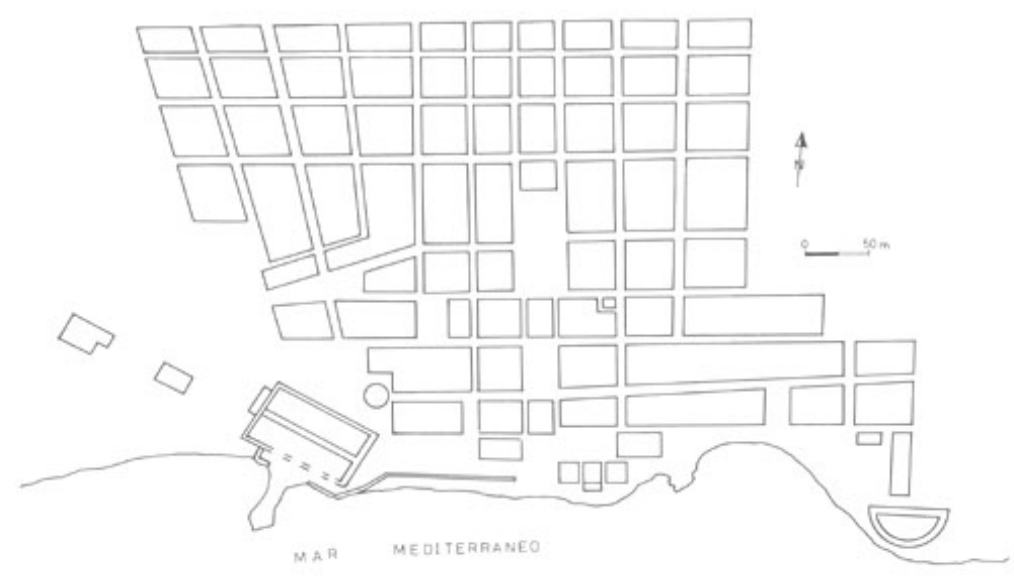

FIGURA 4. Planta de Torrevieja levantada a principios del siglo XIX, siguiendo unas directrices ortogonales. [163]

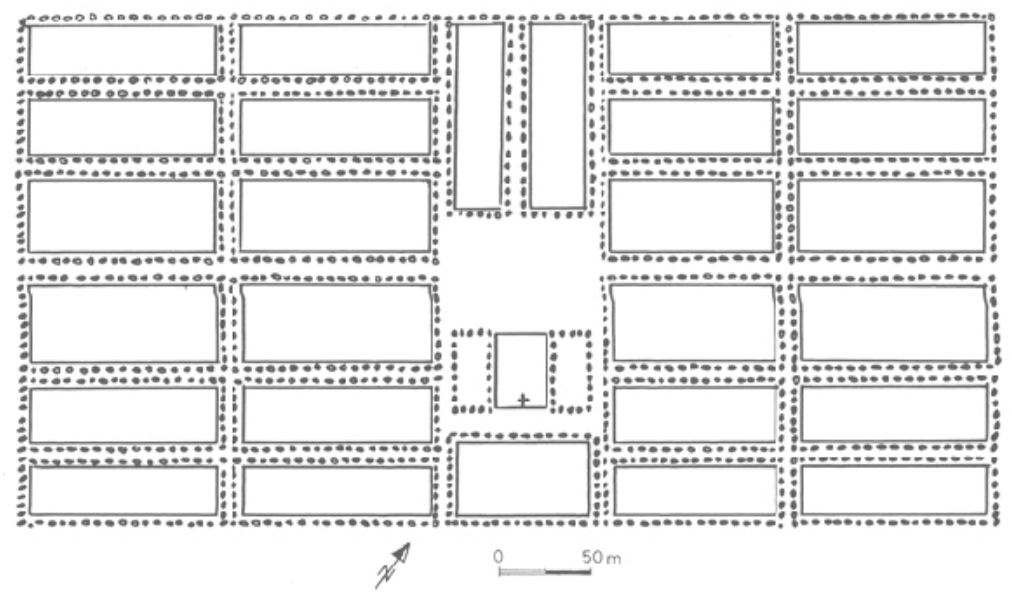

FIGURA 5. Nueva planta del Almoradí post-seísmo. En esta población, como en las restantes, se dispuso una doble hilera de árboles (moreras) en su callejero. [164] 


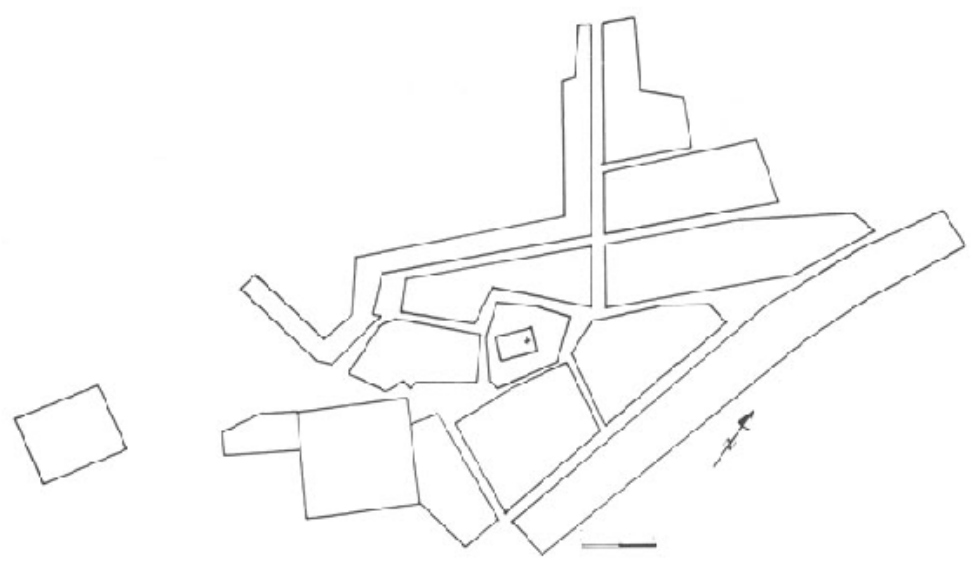

FIGURA 6. Plano de la población de Almoradí en fecha anterior a 1829. [165]

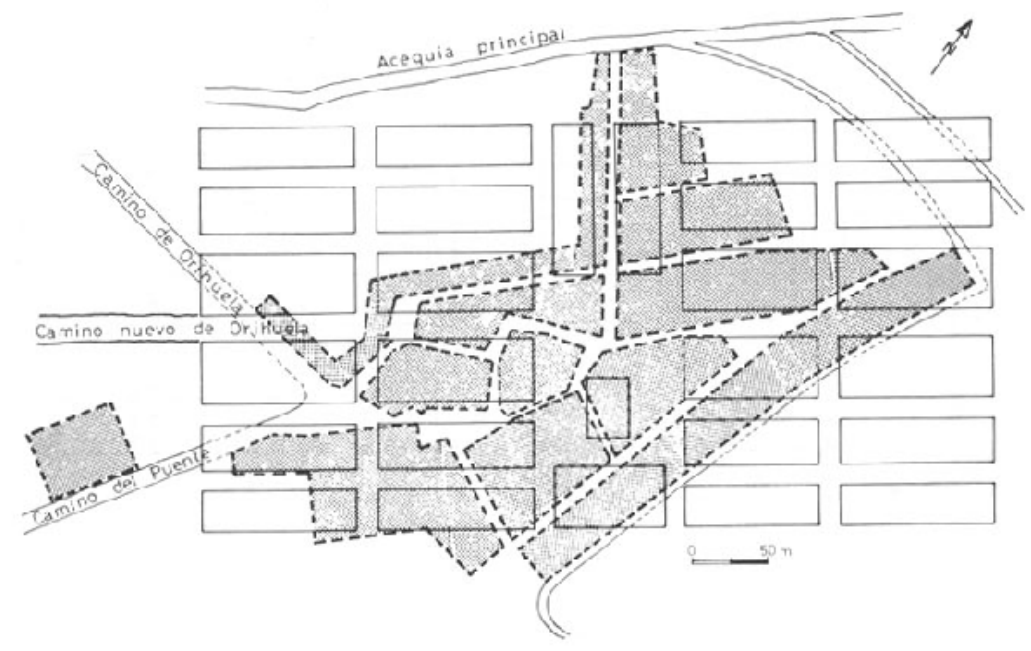

FIGURA 7. Superposición de las dos plantas de Almoradí (figuras 5 y 6). El casco antiguo de trazado irregular queda constreñido por la red de canalizaciones de riego, la cual fue cubierta por imperativo del nuevo trazado urbano. [166] 


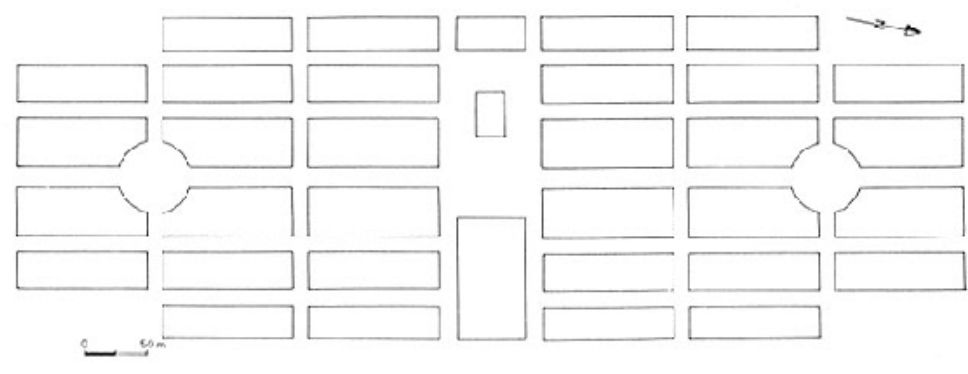

FIGURA 8. Trazado urbano de la nueva Guardamar. Nótese que la plaza central queda flanqueada por otras dos circulares que rompen la monotonía del damero. [167]

extremos, antes de las últimas manzanas, y en el eje longitudinal se abrieron dos plazas circulares de gran belleza, lo que llevó a decir a su arquitecto que Guardamar «iba a ser el pueblo más bonito del Reino». La reconstrucción se efectuó sobre un llano próximo a su primitivo emplazamiento, que estaba situado alrededor de un castillo, el cual dominaba la última colina existente en la margen derecha del río Segura poco antes de la desembocadura (figura 8).

El más pequeño de los pueblos reconstruidos fue Benejúzar, con 186 viviendas de $10 \mathrm{a}$ 27 metros de largo y 17 a 20 de fondo, comprendidas en 13 manzanas; su trazado cuadrado lo forman cuatro calles paralelas cortadas por tres perpendiculares y con una plaza central de 121 metros de largo por 111 de ancho donde al igual que en las otras localidades se levantó la iglesia. Primitivamente la población estaba situada en la ribera izquierda del río Segura dentro de su campo de inundación, pero a raíz del terremoto se reedificó en la ribera opuesta, en un llano a mayor altura que el río, emplazamiento más idóneo para evitar las inundaciones. Los terrenos fueron adquiridos a D. Juan Roca y Carrasco, Conde de Pino Hermoso, a cuya familia pertenecía el señorío del lugar ${ }^{24}$.

En las restantes poblaciones, afectadas total o parcialmente por el terremoto, la reconstrucción se hizo en base a las mismas reglas adoptadas para las anteriores, aprovechando lógicamente lo que todavía existía. En esta tarea colaboraron sus respectivos dueños territoriales. Se trata de pequeños caseríos distribuidos en la huerta, como Daya Nueva, que pertenecía a los Marqueses de Dos Aguas y que constaba de una calle ancha y cómoda ${ }^{25}$; Daya Vieja, de los Condes de Pino Hermoso, formada por una calle y una plaza ${ }^{26}$, y Formentera, que se levantó a expensas del Marqués de Algorfa D. Carlos Pérez de Sarrio, y comprendía una gran plaza cuadrangular de casas de un solo piso, circundada de olmos y álamos, y con unas treinta y cinco

${ }^{24}$ FIGUERAS PACHECO, F.: «Provincia de Alicante» en Geografia General del Reino de Valencia, dirigida por F. Carreras Candi, Barcelona, Alberto Martín S.d., t. IV, pág. 878.

${ }^{25}$ FIGUERAS PACHECO, F.: Op. cit., pág. 887.

${ }^{26}$ MADOZ, P.: Op. cit., t. VII, pág. 364. 
barracas alrededor del pueblo ${ }^{27}$.

En las villas de las Pías Fundaciones, Dolores y San Fulgencio, se siguió el trazado, ya ortogonal, marcado escasamente un siglo antes por el Cardenal Belluga, promotor y creador de estas dos poblaciones. El primer núcleo estaba formado aproximadamente por setecientas casas distribuidas en seis calles y tres plazas ${ }^{28}$, y el segundo por cuarenta y dos casas y varias barracas alineadas en dos calles y una plaza ${ }^{29}$.

De las localidades dañadas parcialmente por el terremoto, la que resultó más afectada fue Rojales, para la que Larramendi también concibió un nuevo trazado, dado su callejero irregular y la división en dos que a su paso producía [168] el río Segura; la reedificación según el arquitecto debía efectuarse en la margen izquierda del río, pero al no haber sido destruida totalmente se optó por la remodelación de sus viviendas (378), construyéndose tan sólo seis nuevas, y formando dos plazas en los ensanchamientos; de ahí que Rojales no ofrezca la simetría de los pueblos de nueva construcción (vide. figuras 9 y 10).

Como apuntábamos se construyeron en total 3.108 viviendas, 1.329 en las nuevas poblaciones, de las que 328 se entregaron a mujeres que habían enviudado a raíz del terremoto y a gentes que carecían de recursos, y las otras fueron levantadas por sus dueños, ayudados con los fondos destinados a tal efecto; en las restantes localidades fueron recompuestas 1.025 casas en edificación compacta y 754 diseminadas por la huerta.

\section{Costo de la reconstrucción}

El 18 de junio de 1832, el Obispo de Orihuela presentaba en la Secretaría de Estado y del Despacho de Gracia y Justicia el resumen de las cuentas generales de lo gastado en la reedificación de los pueblos destruidos por el terremoto, como encargado que fue por el rey de la administración de los 8.470.854 reales de vellón recaudados en las Juntas de Socorro, fondos que se distribuyeron de la siguiente manera: 6.035.880 reales empleados en la construcción de 3.108 viviendas en las nuevas poblaciones, así como en la huerta y pueblos afectados (vide. tabla adjunta); 1.332.132 reales dados a los habitantes de estas casas como ayuda en metálico, aparte de entregas gratuitas de trigo y diversos enseres; 139.778 reales en concepto de salarios a los empleados en las obras y 682.960 reales que se invirtieron en la construcción de cuatro parroquias provisionales, en la recomposición de otras trece y en la obra de las tres nuevas parroquias que se estaban levantando en Guardamar, Almoradí y Benejúzar. La suma de todas estas partidas hacía un total gastado de 8.190 .759 reales, hasta la fecha de referencia; quedaban todavía en tesorería 280.103 reales, de los que 250.000 se emplearían en la terminación de las iglesias empezadas y 30.103 reales en ayudas a los huérfanos del terremoto ${ }^{30}$.

\section{CONCLUSIÓN}

Después del terremoto es evidente que se introdujeron en la comarca del Bajo Segura unas pautas urbanísticas que se puede calificar de nuevas, aunque contaban con los precedentes de las Pías Fundaciones (s. XVIII) y de Torrevieja, por cuanto en ocasión del seísmo todas las poblaciones que se reedificaron, se dispusieron según una trama ortogonal de planta cuadrada

\footnotetext{
${ }^{27}$ MADOZ, P.: Op. cit., t. VIII, pág. 142.

${ }^{28}$ MADOZ, P.: Op. cit., t. VII, pág. 395.

${ }^{29}$ MADOZ, P.: Op. cit., t. VIII, pág. 256.

${ }^{30}$ GACETA DE MADRID, martes 7 de agosto de 1832, número 94, suplemento.
} 
o rectangular; únicamente Guardamar presenta una mayor variedad, al incorporar dentro de su plano rectangular, además de la plaza central cuadrada, dos plazas laterales circulares que rompen la rigidez del trazado urbano hipodámico. [169]

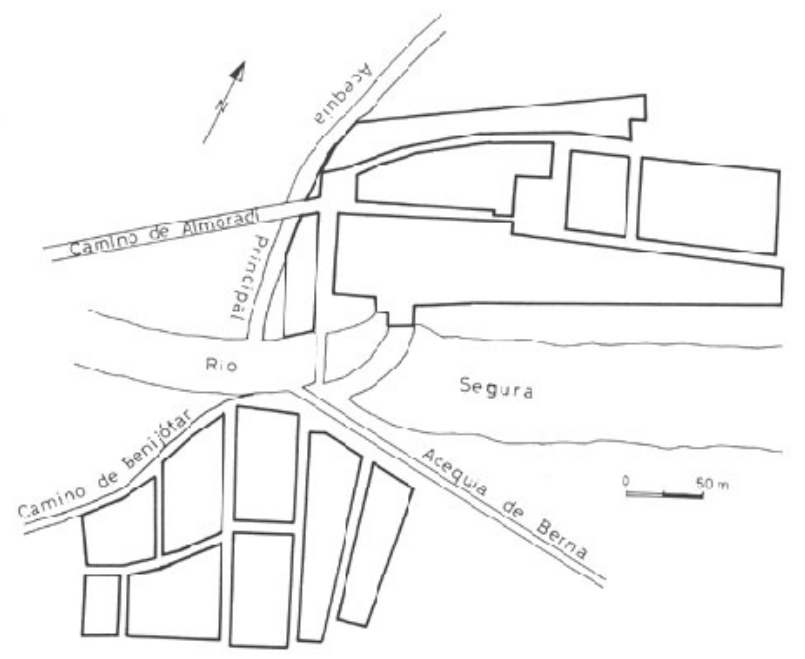

FIGURA 9. Plano de Rojales de 1829, población que será destruida parcialmente en esta fecha. Se aprecia cómo se estructura en dos núcleos separados por el río Segura, cuya traza queda condicionado por su cauce, así como por las acequias y caminos. [170]

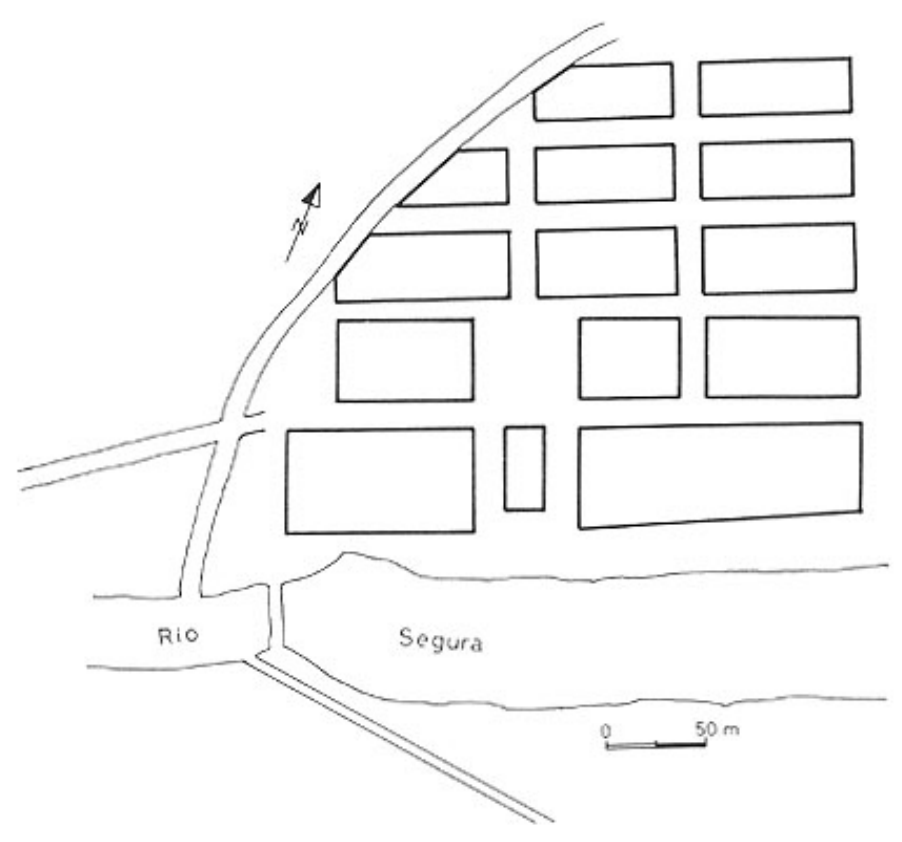


FIGURA 10. Planta levantada por Larramendi para la reconstrucción de Rojales, la cual no se llevó a término. Se repite una vez más el trazado hipodámico, que afectaría únicamente a la margen izquierda. [171]

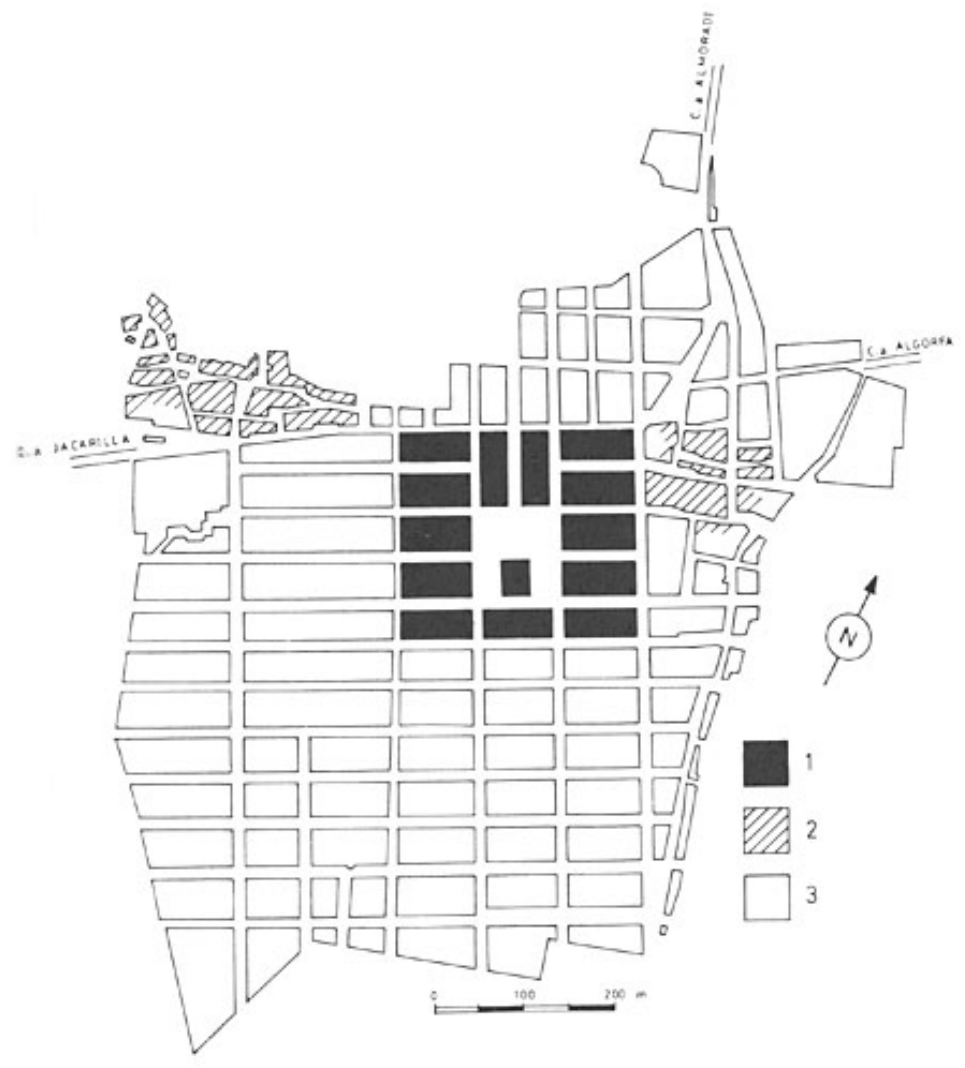

FIGURA 11. Desarrollo actual de Benejúzar: 1. Planta de la reconstrucción de 1829; 2. Caseríos no asolados por el seísmo, cuyo callejero irregular contrasta netamente con el resto del trazado urbano; 3. Ensanche posterior, donde se observa la continuidad de la directrices marcadas por Larramendi. [172]

Se toma como ideal el plano ortogonal entre otras razones por su facilidad de ejecución al tratarse de una área llana; esto condiciona el futuro crecimiento de la población, teóricamente sin limitación alguna, en la dirección señalada en la trama inicial. Esto se ha cumplido sin dificultad en la mayoría de las poblaciones, excepto en algún caso, como es el de Benejúzar, que, en el plano actual (vide. figura 11), refleja un trazado irregular en los extremos del casco urbano, producto de que la población se reedificó entre dos caseríos preexistentes (de más de 60 casas cada uno) y que, con el tiempo quedaron incorporados, con su trama anárquica, dentro del perímetro urbano.

Novedad también es la importancia que a partir de entonces va a cobrar el arbolado en estas poblaciones, elemento que en aquellas fechas fue incorporado a la fisonomía de calles y plazas. El árbol, que anteriormente estaba excluido de la calle y reservado para la intimidad de las fincas particulares, pasa a ser una componente característica de estas poblaciones, y no solamente por su función estética, al suavizar la dureza del trazado urbano, sino también por una función práctica como es la de proporcionar sombra en la época estival, amén del aprovechamiento que de él se puede obtener. 
Extracto de las cuentas presentadas por el Obispo de Orihuela de lo gastado en las edificaciones y de las ayudas distribuidas (año 1832)

\begin{tabular}{llrr}
\hline $\begin{array}{l}\text { Poblaciones } \\
\text { afectadas }\end{array}$ & $\begin{array}{l}\text { Edificaciones } \\
\text { (compacto y diseminado) }\end{array}$ & $\begin{array}{c}\text { Presupuesto } \\
\text { (en reales) }\end{array}$ & $\begin{array}{c}\text { Socorros a los } \\
\text { vecinos (en reales) }\end{array}$ \\
\hline Almoradi & 335 casas en 26 manzanas & 1.364 .479 & 332.474 \\
Almoradí & 754 casas en su huerta & 735.469 & 155.585 \\
Guardamar & 540 casas en 34 manzanas & 1.808 .692 & 138.748 \\
Benejúzar & 186 casas en 13 manzanas & 614.064 & 131.060 \\
Torrevieja & 268 casas en 27 manzanas & 803.951 & 222.364 \\
Rojales & $\begin{array}{l}\text { 6 casas nuevas y recompo- } \\
\text { Dolores y S. Fulgencio de 378 recomposición de 366 casas }\end{array}$ & 373.645 & 116.566 \\
Otras poblaciones & recomposición de 275 casas * & 138.780 & 68.169 \\
\hline Total & 3.108 edificaciones & 6.035 .880 & 1.332 .132 \\
\hline
\end{tabular}

* San Miguel de Salinas con 133 casas; Torre de la Mata con 24; Benijófar con 75;

Formentera con 13; Rafal con 22; Dayas y Puebla con 8 viviendas. 